\title{
Immunodetection of aquaporin 5 in sheep salivary glands related to pasture vegetative cycle
}

\author{
Paola Scocco ${ }^{1}$, Marina Aralla ${ }^{2}$, Andrea Catorci ${ }^{1}$, Carlo Belardinelli ${ }^{3}$, \\ Silvana Arrighi ${ }^{2}$
}

\author{
${ }^{1}$ School of Environmental Sciences, Università di Camerino, Italy \\ ${ }^{2}$ Department of Veterinary Sciences and Technologies for Food Safety, \\ Università degli Studi di Milano, Italy \\ ${ }^{3}$ Department of Prevention, Unit of Hygiene of Animal Origin Food (ASUR10), Camerino, Italy
}

\begin{abstract}
Mammalian aquaporins (AQPs) are a family of at least 13 integral membrane proteins expressed in various epithelia, where they function as channels to permeate water and small solutes. AQP5 is widely expressed in the exocrine gland where it is likely involved in providing an appropriate amount of fluid to be secreted with granular contents. As regards AQP5 expression in the salivary glands, literature is lacking concerning domestic animal species. This study was chiefly aimed at immunohistochemically investigating the presence and localization of AQP5 in sheep mandibular and parotid glands. In addition, AQP5 immunoreactivity was comparatively evaluated in animals fed with forage containing different amounts of water related to the pasture vegetative cycle, in order to shed light on the possible response of the gland to environmental modifications. Moderate AQP5-immunoreactivity was shown at the level of the lateral surface of mandibular serous demilune cells, not affected by the pasture vegetative cycle or water content. On the contrary, the parotid gland arcinar cells showed AQP5-immunoreactivity at the level of apical and lateral plasma membrane, which was slight to very strong, according to the pasture vegetative development and interannual climatic variations. AQP5 expression is likely due to its involvement in providing appropriate saliva fluidity. Indeed, the lowest AQP5 immunoreactivity was noticed when food water content increased. (Folia Histochemica et Cytobiologica 2011; Vol. 49, No. 3, pp. 458-464)
\end{abstract}

Key words: AQP5, sheep, salivary glands, pasture vegetative cycle, immunohistochemistry

\section{Introduction}

Mammalian aquaporins (AQPs) are a class of at least 13 integral membrane proteins that facilitate rapid passive movement of water, characterized by having a sequence of about 270 amino acids, forming six transmembrane helical domains spanning the lipid bilayer, in such a way as to form two hemichannels, giving origin to an hourglass-shaped channel through which water may pass [1-3].

\footnotetext{
Correspondence address: S. Arrighi,

Dipartimento di Scienze e Tecnologie Veterinarie per la Sicurezza Alimentare, Laboratorio di Anatomia, Via Trentacoste 2, 20134 Milano, Italy; tel.: (+ 39 02) 503157 41, fax: (+ 39 02) 503157 46; e-mail: silvana.arrighi@unimi.it
}

AQPs exist in plants, bacteria, insects and several members of the animal kingdom. They are expressed in various epithelia where they function as channels allowing the permeability of water and small solutes. Subsets of epithelia where AQP water channels are expressed have a 10- to 100-times greater capacity for water permeation compared to those devoid of these proteins [4]. AQPs 0 , 1, 2, 4, 5 and 6 are mainly water selective, while AQPs 3, 7, 9 and 10 also transport glycerol, urea and neutral solutes and are called aquaglyceroporins $[4,5]$. AQP8 might permeate urea in addition to water [6]. AQP11 and AQP12 belong to a new subfamily, the superaquaporins [7].

AQPs represent constitutive elements of the plasma membrane in most secretory cell types of exocrine glands [8-14]. Recently, their presence has been demonstrated in secretory granules and vesicles, indicating an involvement in volume regulation of these structures [15]. 
Recent research on humans and laboratory mammals, aimed at identifying aquaporins and aquaglyceroporins in the digestive system, has demonstrated that AQP water channels are involved in the physiologic processes of digestion and absorption of the ingesta $[16,17]$. Moreover, AQPs have been identified as co-factors in the etiopathogenesis of some gastroenteric disorders [18-21]. The presence of channels specific for water, urea and other solutes at the membrane level of gastrointestinal glandular cells can be modulated, or can influence in turn hormones, enzymes and pro-enzymes, mediators and other chemical substances, such as vasopressin, Vasoactive Intestinal Peptide, capsaicin, ethanol, histamine and pepsinogen [16, 17, 22-29].

In the salivary glands, AQP5 is probably involved in providing for an appropriate amount of fluid to be secreted $[15,30]$. In particular, in rat salivary glands, AQP5 is highly expressed in the apical plasma membrane of serous acinar cells, in the secretory canaliculi and in the intercalated duct cells. On the other hand, it is lacking in mucous acinar cells and in striated ducts, indicating its important role in saliva production [14], further supported by the observation of markedly depressed rates of salivary secretion in APQ5-deficient mice [31]. The significance of AQP5 to human diseases may include important disorders of the lung, airways, sweat glands, lacrimal glands and the salivary glands [13, 31, 32]. A defective trafficking of AQP5 has been found in salivary gland biopsies of some patients with Sjögren's syndrome [33] where an abnormal distribution of AQP5 in salivary gland acini is likely to contribute to the deficiency of fluid secretion.

Literature on salivary gland AQP5 expression is lacking regarding domestic animal species, so this study was chiefly aimed at immunohistochemically investigating the presence of AQP5 in sheep mandibular and parotid glands.

In addition, its expression was evaluated in animals fed with three different forages depending on the pasture vegetative cycle and containing different water amounts. This investigation is part of a wider, multidisciplinary study focused on the morphofunctional variations of the digestive apparatus related to pasture vegetative cycle, aimed at shedding light on the response of biological systems (represented in this case by the salivary glands) to environmental modifications, especially climatic ones, and to their repercussions on farming management planning.

\section{Material and methods}

Animal feed, grassland features and forage water amount detection. Animals utilized for this study were fed dry hay and cereals throughout the winter season, then nourished with fresh grass during the pasture vegetative cycle. While freely grazing, no additional feed was given to animals during the permanence on the pasture. Animals were allowed water twice a day at both sheep-fold and natural pasture. The natural pasture comprised Bromus erectus dominated stands, in the sub-Mediterranean central Apennines of Italy. Forage was usually full-dried in summer because of drought stress and lacking of leaves re-growth. The seasonal length of leaves re-growing depends on the amount of annual rainfall, so it usually changes year by year.

Two consecutive pasture vegetative cycles (2007 and 2008) were considered for this study to obtain above-ground phytomass samples by mowing carried out every 15 days on fenced permanent plots $(5 \mathrm{~m} \times 5 \mathrm{~m})$ during the grazing season (end of April to end of October). Mowing plots were part of the pasture areas and were representative of the natural plant communities mosaic where animals used for the experiment were allowed to graze [34]. For each plot, and in each time point considered for the experiment, five pasture samples were harvested. The specimens obtained were kiln-dried at $90^{\circ} \mathrm{C}$ until reaching a constant weight [35]. Samples of dry hay and rehydrated cereals used for animal nourishment during the winter were similarly treated.

Tissue collection and processing. Fragments of mandibular and parotid glands were collected upon slaughtering from 18 adult female sheep of the Fabrianese breed. The animals had been fed dry hay and cereals throughout the winter, then nourished with fresh grass during the pasture vegetative cycle. Sheep were slaughtered at different times of the year, thus salivary gland specimens were collected from animals belonging to three experimental groups: 1) at the end of the winter (May), exclusively fed with sheep-fold diet ( $\mathrm{n}=3$ ); 2) 15 days after the maximum pasture flowering (beginning of August) $(\mathrm{n}=3)$; and 3) 15 days after the maximum pasture dryness (halfway through October) $(\mathrm{n}=3)$. The experiment was repeated over 2007 and 2008, utilizing the same sampling protocol.

Samples were immediately fixed by immersion either in Carnoy's fluid followed by a post-fixation with calcium acetate 2\%-paraformaldehyde $4 \%$ [36] or in paraformaldehyde $4 \%$ [13], dehydrated in a graded series of ethanol, cleared in xylene and embedded in paraffin wax. Both fixatives were freshly prepared every time.

AQP5 immunohistochemistry. Sections of all specimens and controls included in the study were simultaneously processed in the same session of immunohistochemistry. Antibodies, buffer and revelation solutions were made freshly for the experiment.

After de-waxing, serial sections ( $4 \mu \mathrm{m}$ thick) obtained from specimens fixed with either fixative were washed and immersed in a freshly prepared $3 \% \mathrm{H}_{2} \mathrm{O}_{2}$ solution for 15 
min to block the endogenous peroxidase activity. This was followed by incubation in 1:20 normal goat serum (DakoCytomation, Denmark, code X0907) in Tris-Buffered Saline (TBS: $0.05 \mathrm{M}$ Tris/ $\mathrm{HCl}, 0.15 \mathrm{M} \mathrm{NaCl}$ ) for $30 \mathrm{~min}$ to prevent background prior to incubation with primary antiserum. Sections were then incubated overnight in a humidity chamber at room temperature using rabbit polyclonal antibodies against rat AQP5 (Alpha Diagnostic International, San Antonio, TX, USA; Cat \# AQP51-A) diluted 1:100 in TBS containing $2 \%$ of normal goat serum. Subsequently, the sections were rinsed $3 \times 5 \mathrm{~min}$ in TBS and incubated for $30 \mathrm{~min}$ at room temperature with biotinylated goat anti-rabbit immunoglobulins (Vector Laboratories, Inc., Burlingame, CA, USA, code BA1000) diluted 1:200. Streptavidin-Biotin/Horseradish Peroxidase Complex (Vectastain ${ }^{\circledR}$ ABC Kit, code PK-4001, Vector Laboratories, Inc., Burlingame, CA, USA) was employed for detection. The sections were washed $3 \times 5$ min with TBS before applying liquid 3,3'-diaminobenzidine solution (DAB + Chromogen, DAKO code \# K3467) for up to ten min. Sections were counterstained with Mayers' hematoxylin, dehydrated, and permanently mounted using Eukitt ${ }^{\circledR}$ (Bioptica, Milan, Italy).

Staining controls. Sections of human and rat salivary gland (respectively acquired from University tissue collection and the experimental laboratory animal facility of Milan Veterinary Faculty) served as positive controls for AQP5-immunoreactions. The specificity of the immunostainings was tested by negative controls, performed by: 1) use of non-immune rabbit serum (DakoCytomation; code \# X 0903) in place of specific antisera; and 2) omission of the first layer. All of them resulted in an absence of immunoreaction.

The evaluation of staining intensities was based on subjective estimates independently performed by three authors. Slides were observed and photographed under an Olympus BX51 photomicroscope equipped with a digital camera and DP software (Olympus, Tokyo, Japan) for computer-assisted image processing.

\section{Results}

\section{Forage water amount detection}

Data obtained from the drying of pasture samples are reported in Figure 1. The trend in water content was similar in the two examined years, with a decrease of water percentage in the forage during the summer period, lasting from the end of July to the beginning of September. During 2007, a rather dry year, a sudden decrease in the water content occurred at the end of September. During 2008, a rather rainy year, an increase in water content percentage was observed from the mid of August. The variation in water content among the samples from the same time point ranged from $1.2 \%$ to $2.7 \%$.

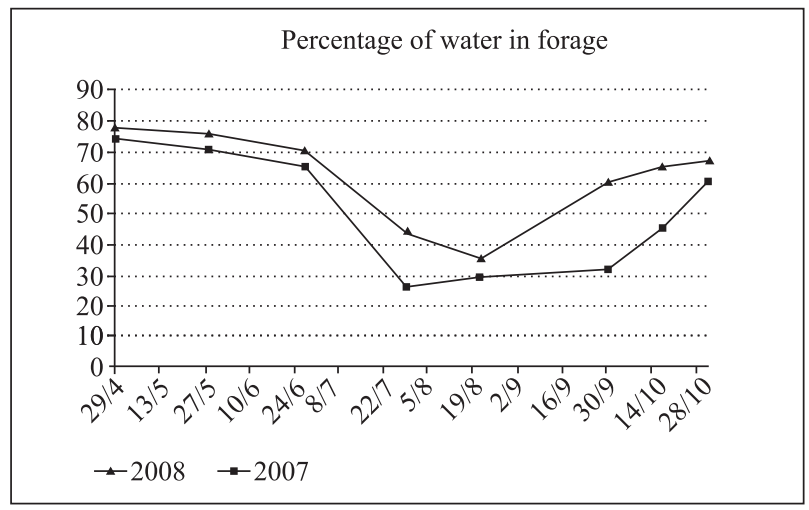

Figure 1. Percentages of water content are shown, detected from drying of pasture samples. The graphs were obtained by elaborating the results acquired in the two examined years at the dates indicated at the bottom of the picture

The dry hay and rehydrated cereals used for animal nourishment during the winter had a water content of $25 \%$.

\section{Immunohistochemistry}

The best immunohistochemical results were obtained in Carnoy's-fixed tissues. They are summarized in Table 1 and shown in Figure 2. In both examined glands, AQP5-immunoreactivity was present in the secretory components only, whereas epithelial cells lining any ductal segment never showed immunoreaction. Mandibular gland showed moderate AQP5-immunoreactivity at the level of the lateral plasma membrane of the serous demilunes (Figure 2A, inset). No reactivity was detected in the mucous adenomeres of the gland (Figure 2A). The slight AQP5-immunoreactivity detected in the mandibular gland was not affected by the pasture vegetative cycle and relative water content.

The parotid gland showed AQP5-immunoreactivity at the level of the apical and lateral plasma membranes of the acinar cells (Figure 2B, inset). AQP5-immunoreactivity was very strong in the parotid gland of group 1 sheep, immediately after going out from the sheep-fold (Figure 2B).

Moreover, AQP5-immunoreactivity was slight to strong in the parotid gland according to the vegetative development and the climatic variations. During the first year of the experiment (2007), a decreased AQP5-immunoreactivity was observed in the parotid gland of group 2 sheep, which were nourished throughout the maximum flowering of the pasture (Figure 2C) if compared to the reactivity shown immediately after going out from the sheep-fold (group 1 sheep, Figure 2B). AQP5-immunoreactivity was strong in the parotid glands of group 3 sheep, ana- 

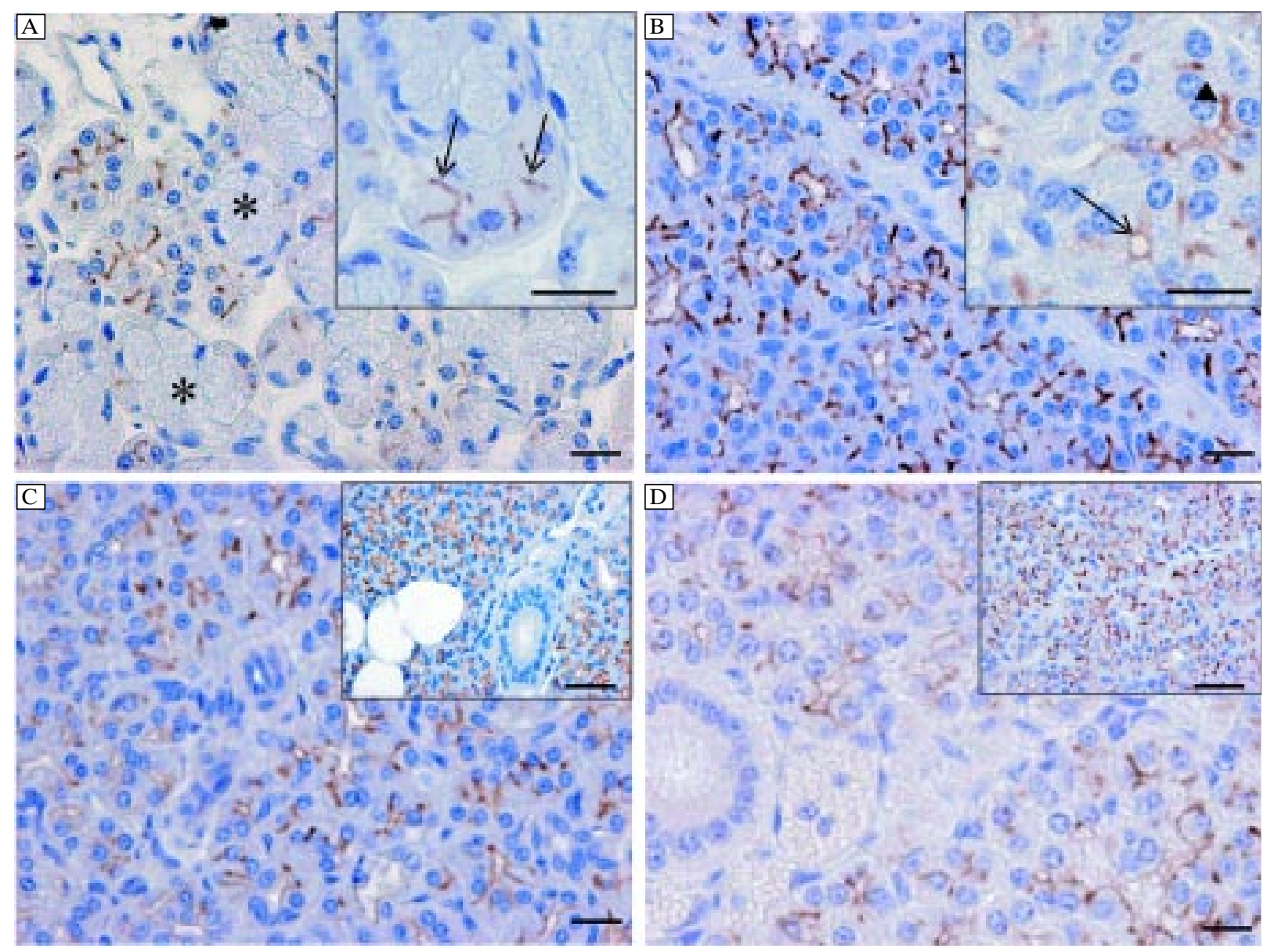

Figure 2. Immunohistochemical analysis of AQP5 distribution in sheep salivary glands. A. In the sheep mandibular gland, AQP5 is present at the level of the serous demilunes while it is lacking at the level of mucous acini (*); in particular, AQP5 immunoreactivity has been evidenced in the lateral plasma membrane of serous cells ( $\uparrow$ ), see inset. B. Parotid gland: AQP5-immunoreactivity of the acinar cells detected at the end of the winter (group 1 sheep) was very strong. In particular, AQP5 is apically expressed in the serous acinar cells $(\uparrow)$ and in the lateral plasma membrane $(\boldsymbol{\Delta})$, see inset. C. In the parotid gland collected 15 days after the maximum pasture flowering during the first year of the experiment (group 2 sheep), moderate AQP5-immunoreactivity can be noticed, lower compared to group 1. During the maximum pasture dryness, AQP5 reactivity increased (see inset). D. The AQP5-immunoreactivity was slight in the group 2 sheep samples during the second year of the experiment, and moderately increased in group 3 sheep samples (see inset).

Scale bars: A, B, C, D = 20 $\mu \mathrm{m}$; insets in A, B $=20 \mu \mathrm{m}$; insets in $\mathrm{C}, \mathrm{D}=40 \mu \mathrm{m}$

Table 1. AQP5-immunoreactivity in sheep salivary glands related to pasture vegetative cycle

\begin{tabular}{|l|c|c|c|c|c|}
\hline \multirow{2}{*}{$\begin{array}{l}\text { Sheep salivary gland } \\
\text { AQP5-immunoreactivity }\end{array}$} & \multicolumn{3}{|c|}{ Mandibular gland } & \multicolumn{2}{c|}{ Parotid gland } \\
\cline { 2 - 6 } & Mucous acini & Serous demilunes & Ducts & Serous acini & Ducts \\
\hline Sheep Group 1, years 2007/2008 & - & $+/++$ & - & +++ & - \\
\hline Sheep Group 2, year 2007 & - & $+/++$ & - & +++ & - \\
\hline Sheep Group 3, year 2007 & - & $+/++$ & - & ++ & - \\
\hline Sheep Group 2, year 2008 & - & $+/++$ & - & + & - \\
\hline Sheep Group 3, year 2008 & - & $+/++$ & - & $+/++$ & - \\
\hline
\end{tabular}

Intensity of immunoreaction is arbitrarily identified as: + slight,$+/++$ moderate,++ strong, +++ very strong, - no immunoreactivity detected

lyzed after a period of nourishment throughout the maximum dryness of the pasture (Figure 2C, inset). During the second year of the experiment (2008), re- sults were similar to those obtained in 2007 even if the expression of AQP5 was lower. In fact, AQP5-immunoreactivity was slight in samples collected from 
group 2 sheep after feeding throughout the maximum flowering of the pasture (Figure 2D), and moderate in samples collected from group 3 sheep after feeding for the duration of the maximum dryness of the pasture (Figure 2D, inset). No appreciable variability of staining intensity was shown among the samples of the animals pertaining to the same group.

\section{Discussion}

Surprisingly, the best immunohistochemical results were obtained in Carnoy's-fixed tissues. Indeed, formaldehyde is one of the most popular fixatives in immunohistochemistry, partly because of its low cost and manageability, but mainly because of its aptitude in preserving morphological features with few artefacts. Nevertheless, formaldehyde fixation results in a variable loss of immunoreactivity by its hiding or damaging the antibody binding sites. Enzyme digestion or heat-induced epitope retrieval may help in revealing unavailable sites $[37,38]$ but are invariably harmful to the tissue integrity and might reduce the intensity of the immunostaining. Alcohol and alcohol-based fixatives such as Carnoy's are often superior to formaldehyde in retaining antigenicity $[39,40]$ and this is further demonstrated by the results of our experiment (not shown).

In both examined glands, AQP5-immunoreactivity was present in the serous secretory components only; the mandibular gland showed AQP5-immunoreactivity restricted to lateral plasma membrane of the serous demilunes, while the parotid gland showed AQP5-immunoreactivity at both the apical and lateral plasma membranes of the acinar cells.

The movement of fluid occurs in the cell plasma membrane through both the transcellular and paracellular pathway $[28,41]$. Transcellular water movement can be successfully attained thanks to the presence of water channels in both apical/lateral and basal membranes. In this study, AQP5 was present in the apical and lateral membranes of serous cells in the sheep salivary glands. The basolateral membrane is believed to have high permeability in the salivary gland acinar cells, and AQP5 at luminal surface of the acinar cells is implied to serve as a rate-limiting step in the water transport across the cells [42, 43]. Murakami et al. [28] showed that in the rat submandibular gland, AQP5 is involved in the control of the junctional fluid transport system (JFT system) as an osmosensor able to influence the paracellular pathway. On the other hand, Krane et al. [31] demonstrated an AQP5 involvement in the water transcellular transport in mouse salivary glands. Our results in the sheep salivary glands show that AQP5 is abundantly expressed in the luminal membranes of serous acinar cells. The positive immunoreactivity, likely localized at the level of intercellular canaliculi that radiate from the luminal space of the serous acini of the parotid and mandibular glands, indicates that the presence of AQP5 might increase the functionality of this small apical surface area. As for the parotid gland, the data also agrees with recent findings $[13,44]$ indicating the role of AQP5 in the secretive process at apical membrane level in human parotid acinar cells.

The moderate reactivity of the mandibular gland did not change, either at different times of the year or between the two examined years. But the parotid gland showed an AQP5 reactivity ranging from slight to very strong according to the vegetative development and the interannual climatic variations. To be precise, during 2007, animals grazed on a pasture which contained, at the maximum of flowering, a water percentage ranging from 65 to 30 , whereas in the period of maximum dryness, the water content varied from $30 \%$ to $45 \%$, and there was a period of about 70 days in which the water content was less than $50 \%$. During 2007, the AQP5 expression in sheep parotid gland was higher than in 2008. In fact, 2008 was a particularly rainy year, and the pasture percentage of water ranged from 70 to 40 in the period of maximum flowering, and from 40 to 65 in the period of maximum dryness, in which the content of water in the pasture was less than $50 \%$ for only 40 days.

Saliva is the principal means of mixing food as well as of dissolving the sapid substances, and its secretion can be increased by different kinds and intensities of stimuli; food ingestion causes a saliva secretion, the amount of which is inversely linked to the food water content; in addition, ruminant parotid glands perform a continuous secretion $[45,46]$. Thus, it is not surprising that only the sheep parotid gland was affected by the hydration of the pasture.

The required additional saliva supply when the food water amount is low may be assured by an increased AQP5 expression. This hypothesis is further supported by our findings showing that:

- AQP5 staining intensity decreased in the maximum pasture flowering period, when the water amount is higher than in both the winter and maximum pasture dryness period, when samples showed highest AQP5 reactivity;

- the variability in APQ5 immunoreactivity was higher during 2007 than 2008, due to the required additional saliva supply linked to the longer pasture dryness period.

Actual findings and acquired knowledge on salivary glands [36, 47-50] allow us to hypothesize for the sheep parotid gland a role in the production of the amount of saliva mainly involved in the lubrica- 
tion and mixing of chewed food, while the mandibular gland produces saliva more involved in defensive functions. If this is the case, it is not surprising that only the parotid gland was affected by the hydration of the pasture.

It should be noted that there is a close relation between the salivary gland histophysiology and the pasture biological system, evidenced by the rapid functional response of the parotid gland to the environmental changes. This consideration adds to other evidence gathered from the study of morphofunctional modifications of the sheep digestive system linked to environmental variations [51-53], and should be taken into account in managing a natural farming system.

\section{Acknowledgements}

The authors wish to thank Dr. P. Coliolo and Mrs. M.G. Mancini for their excellent technical assistance. This work was supported by grants form Marche Region, Project n ${ }^{\circ} 16$ L.R. 37/99-DGR 1234/05 Zootechny and fire prevention.

\section{References}

1. Jung JS, Preston GM, Smith BL, Guggino WB, Agre P. Molecular structure of the water channel through aquaporin CHIP. The hourglass model. J Biol Chem. 1994;269:14648$-14654$.

2. Murata K, Mitsuoka K, Hirai T et al. Structural determinants of permeation through aquaporin-1. Nature. 2000; 407:599-605.

3. Sui H, Han BG, Lee KJ, Walian P, Jap BK. Structural basis of water-specific transport through the AQP1 water channel. Nature. 2001;414:872-878.

4. Agre P, King LS, Yasui M et al. Aquaporin water channels from atomic structure to clinical medicine. J Physiol. 2002;542:3-16.

5. Yasui M. Molecular mechanisms and drug development in aquaporin water channel diseases: structure and function of aquaporins. J Pharmacol Sci. 2004;96:260-263.

6. Yasui M, Hazama A, Kwon TH, Nielsen S, Guggino WB, Agre P. Rapid gating and anion permeability of an intracellular aquaporin. Nature. 1999;402:184-187.

7. Ishibashi K. New members of mammalian aquaporins: AQP10-AQP12. Handb Exp Pharmacol. 2009;190:251-262 .

8. Raina S, Preston GM, Guggino WB, Agre P. Molecular cloning and characterization of an aquaporin cDNA from salivary, lacrimal, and respiratory tissues. $\mathrm{J}$ Biol Chem. 1995;270:1908-1912.

9. Ishida N, Hirai SI, Mita S. Immunolocalization of aquaporin homologs in mouse lacrimal glands. Biochem Biophys Res Commun. 1997;238:891-895.

10. Ishikawa Y, Eguchi T, Skowronski MT, Ishida H. Acetylcholine acts on M3 muscarinic receptors and induces the translocation of aquaporin 5 water channel via cytosolic $\mathrm{Ca}^{2}$ elevation in rat parotid glands. Biochem Biophys Res Commun. 1998;245:835-840.
11. Matsuzaki T, Suzuki T, Koyama H, Tanaka S, Takata K. Aquaporin-5 (AQP5), a water channel protein, in the rat salivary and lacrimal glands: immunolocalization and effect of secretory stimulation. Cell Tissue Res. 1999;295:513-521.

12. Matsuzaki T, Tajika Y, Suzuki T, Aoki T, Hagiwara H, Takata K. Immunolocalization of water channel, aquaporin-5 (AQP5) in the digestive system. Arch Histol Cytol. 2003;66:307-315.

13. Gresz V, Kwon $\mathrm{TH}$, Gong $\mathrm{H}$ et al. Immunolocalization of AQP5 in rat parotid and submandibular salivary glands after stimulation or inhibition of secretion in vivo. Am J Physiol Gastrointest Liver Physiol. 2004;287:G151-161.

14. Gresz V, Kwon TH, Hurley PT et al. Identification of aquaporin water channels in human salivary glands. Am J Physiol Gastroint Liver Physiol. 2001;281:247-254.

15. Sugiya H, Matsuki-Fukushima M, Hashimoto S. Role of aquaporins and regulation of secretory vesicle volume in cell secretion. J Cell Mol Med. 2008;12:1486-1494.

16. Bodis B, Nagy G, Nemeth P, Mozsik G. Active water selective channels in the stomach: 2001;95:271-275.

17. Cristia E, Amat C, Naftalin RJ, Moreto M. Role of vasopressin in rat distal colon function. $J$ Physiol. 2007;578:413-424.

18. Amlal H, Sheriff S, Soleimami M. Upregulation of collecting duct aquaporin-2 by metabolic acidosis: role of vasopressin. Am J Physiol Cell Physiol. 2004;286:1019-1030.

19. Hardin JA, Wallace LE, Wong JF et al. Aquaporin expression is downregulated in a murine model of colitis and in patients with ulcerative colitis, Crohn's disease and infectious colitis. Cell Tissue Res. 2004;318:313-323.

20. Parvin MN, Kurabuchi S, Murdiastuti K et al. Subcellular redistribution of AQP5 by vasoactive intestinal polypeptide in the Brunner's gland of the rat duodenum. Am J Physiol Gastrointest Liver Physiol. 2005;288:1283-1291.

21. Guttmann JA, Samji FN, Li Y, Deng W, Lin A, Finlay BB. Aquaporins contribute to diarrhoea caused by attaching and effacing bacterial pathogens. Cell Microbiol. 2007;9:131-141.

22. Misaka T, Abe K, Iwabuchi K et al. A water channel closely related to rat brain aquaporin 4 is expressed in acid- and pepsinogen-secretory cells of human stomach. FEBS Lett. 1996;381:208-212.

23. Carmosino M, Procino G, Nicchia GP et al. Histamine treatment induces rearrangements of orthogonal arrays of particles (OAPs) in human AQP4-expressing gastric cells. J Cell Biol. 2001;154:1235-1243.

24. Gallardo P, Cid LP, Vio CP, Sepulveda FV. Aquaporin-2, a regulated water channel, is expressed in apical membranes of rat distal colon epithelium. Am J Physiol Gastrointest Liver Physiol. 2001;281:856-863.

25. Hatakeyama S, Yoshida Y, Tani T et al. Cloning of a new aquaporin (AQP10) abundantly expressed in duodenum and jejunum. Biochem Biophys Res Commun. 2001;287:814-819.

26. Itoh A, Tsujikawa T, Fujiyama Y, Bamba T. Enhancement of aquaporin-3 by vasoactive intestinal polypeptide in a human colonic epithelial cell line. J Gastroenterol Hepatol. 2003;18: 203-210.

27. Laforenza U, Cova E, Gastaldi G et al. Aquaporin-8 is involved in water transport in isolated superficial colonocytes from rat proximal colon. $J$ Nutr. 2005;135:2329-2336.

28. Murakami M, Murdiastuti K, Hosoi K, Hill AE. AQP and the control of fluid transport in a salivary gland. $J$ Membr Biol. 2006;210:91-103.

29. Nagahama M, Ma N, Semba R, Naruse S. Aquaporin 1 immunoreactive enteric neurons in the rat ileum. Neurosci Lett. 2006;395:206-210. 
30. Ishikawa Y, Cho G, Yuan Z, Skowronski MT, Pan Y, Ishida $\mathrm{H}$. Water channels and zymogen granules in salivary glands. J Pharmacol Sci. 2006;100:495-512.

31. Krane CM, Melvin JE, Nguyen HV et al. Salivary acinar cells from aquaporin 5-deficient mice have decreased membrane water permeability and altered cell volume regulation. $J$ Biol Chem. 2001;276:23413-23420.

32. Nielsen S, King LS, Christensen BM, Agre P. Aquaporins in complex tissues. II. Subcellular distribution in respiratory and glandular tissues of rat. Am J Physiol. 1997;273:C1549-1561.

33. Steinfeld S, Cogan E, King LS, Agre P, Kiss R, Delporte C. Abnormal distribution of aquaporin-5 water channel protein in salivary glands from Sjogren's syndrome patients. Lab Invest. 2001;81:143-148.

34. Cesaretti S, Castagna S, Montenegro B, Catorci A. Zootechnical characterization of grassland vegetation in a pastoral system as a tool for biodiversity conservation: a case study of Umbria-Marches Apennines. Inf Bot Ital. 2009;41:247-258.

35. Gratani L, Rossi A, Crescente MF, Frattaroli AM. Ecologia dei pascoli di Campo Imperatore (Gran Sasso d'Italia) e carta della biomassa vegetale. Braun-Blanquetia. 1999;16:227-247.

36. Scocco P, Pedini V. Equine mandibular gland: in situ characterisation of sialoderivatives. Equine Vet J. 2006; 38:410-415.

37. Cookhan B, Kovatich AJU, Miettinen M. Non enzymatic antigen retrieval in immunohistochemistry. Appl Immunohistochem. 1993;1:149-155.

38. Von Wasielewski R, Werner M, Nolte M, Wilkens L, Georgii A. Effects of antigen retrieval by microwave heating in formalin-fixed tissue sections on a broad panel of antibodies. Histochem J. 1994;102:165-172.

39. Menghi G, Scocco P, Materazzi G. Occurrence of endogenous lectins in the mouse submandibular gland. An immunohistochemical approach. Acta Histochem. 1992;92:67-73.

40. Werner M, Chott A, Fabiano A, Battifora H. Effect of formalin tissue fixation and processing on immunohistochemistry. Am J Surg Pathol. 2000;24:1016-1019.

41. Kawedia JD, Nieman ML, Boivin GP et al. Interaction between transcellular and paracellular water transport pathways through Aquaporin 5 and the tight junction complex. Proc Natl Acad Sci USA. 2007;104:3621-3626.

42. Ma T, Song Y, Gillespie A, Carlson EJ, Epstein CJ, Verkman AS. Defective secretion of saliva in transgenic mice lacking aquaporin-5 water channel. J Biol Chem. 1999;274:20071-20074 .

43. Murdiastuti K, Miki O, Yao C et al. Divergent expression and localization of aquaporin 5 , an exocrine-type water channel, in the submandibular gland of Sprague-Dawley rats. Pflugers Arch. 2002;445:405-412.

44. Sasaki Y, Tsubota K, Kawedia JD, Menon AG, Yasui M. The difference of aquaporin 5 distribution in acinar and ductal cells in lacrimal and parotid glands. Curr Eye Res. 2007; 32:923-999.

45. Church DC. Salivary function and production. In: Church DC, ed. The ruminant animal - digestive physiology and nutrition. Waveland Press Inc, Prospect Heights: Illinois, USA; 1993

46. Bortolami R, Callegari E, Beghelli V. Anatomia e fisiologia degli animali domestici. Bologna: Calderini Edagricole; 2000.

47. Schulte BA, Spicer SS, Miller RL. Lectin histochemistry of secretory and cell-surface glycoconjugates in the ovine submandibular gland. Cell Tiss Res. 1985;240;57-66.

48. Menghi G, Materazzi G. Exoglycosidases and lectins as sequencing approaches of salivary gland oligosaccharides. Histol Histopathol. 1994;9:173-183.

49. Scocco P, Menghi G, Ceccarelli P, Pedini V. Lectin histochemistry and identification of $\mathrm{O}$-acetylated sialoderivatives in the horse sublingual gland. Eur J Histochem. 1999;43:47-54.

50. Pedini V, Dall'Aglio C, Mercati F, Pascucci L, Scocco P. Glycoconjugates in sheep buccal glands investigated by conventional and lectin histochemistry. J Appl Anim Res. 2008;34: $49-54$.

51. Ceccarelli P, Scocco P, Catorci A. Anatomy and GIS (Geographical Information Systems): from macro to micro anatomy through the application of an advanced technology. It $J$ Anat Embryol. 2007;112:230.

52. Ceccarelli P, Scocco P, Malfatti A, Cesaretti S, Catorci A. Changes of sheep ruminal mucosae related to seasonal plant growth: when the anatomy is involved in the management of pastural systems. It J Anat Embryol. 2009; 114:72.

53. Ceccarelli P, Pedini V, Catorci A et al. Microanatomy applied to wood fire prevention: keratinization degree of sheep ruminal epithelium related to BCS. Anat Histol Embryol. 2010;39:272. 